\title{
Corrosion Inhibition and Adsorption Properties of Ethanol Extract of Vernonia Amygdalina for the Corrosion of Mild Steel in $\mathrm{H}_{2} \mathrm{SO}_{4}$
}

\author{
A.O. Odiongenyi, ${ }^{1}$ S.A. Odoemelam, ${ }^{1}$ N.O. Eddy ${ }^{2, *}$ \\ ${ }^{I}$ Department of Chemistry, Michael Okpara University of Agriculture, \\ Umudike, Abia State, Nigeria \\ ${ }^{2}$ Department of Chemistry, Ahmadu Bello University, Zaria, Kaduna State, Nigeria
}

Received 19 September 2008; accepted 4 December 2008

\begin{abstract}
Inhibitive and adsorption properties of ethanol extract of vernonia amygdalina for the corrosion of mild steel were studied using weight loss, thermometric, gasometric and IR methods of monitoring corrosion. The results revealed that ethanol extract of Vernonia amygdalina inhibited the corrosion of mild steel. The inhibition efficiency of the extract increased as the concentration of the extract increases. The inhibitor was found to function by being adsorbed on the surface of mild steel. The adsorption of the inhibitor followed the Langmuir adsorption isotherm. IR spectra of the corrosion product (without inhibitor), the extract and the corrosion product (with the inhibitor) confirmed that ethanol extract of vernonia amygdalina is an adsorption inhibitor. Phytochemical studies also revealed that ethanol vernonia amygdalina contains tannin, saponnins, flavanoid and anthraquinone, all of them contributing to the corrosion inhibition. Physical adsorption mechanism has been proposed from the values of some of the thermodynamic parameters obtained.
\end{abstract}

Keywords: corrosion inhibition, mild steel, adsorption, vernonia amygdalina.

\section{Introduction}

The use of inhibitors is one of the best methods of protecting metals against corrosion [1-2]. Most corrosion inhibitors are organic compounds having hetero atoms in their aromatic or long carbon chain [1-3]. However, there is increasing concern about the toxicity of most corrosion inhibitors. The toxic effect does not only affect living organisms but also poison the environment [2].

\footnotetext{
* Corresponding author. E-mail address: nabukeddy@yahoo.com
} 
Due to the toxicity of some corrosion inhibitors, there has been increasing search for green corrosion inhibitors [3]. Inhibitors in this class are those that are environmentally friendly and are gotten from natural products such as plant extracts [4]. Several studies have been carried out on the inhibition of corrosion of metals by plant extract [5-11]. In most of these and other studies, nothing has been reported on the use of ethanol extract of vernonia amygdalina for the inhibition of the corrosion of mild steel in $\mathrm{H}_{2} \mathrm{SO}_{4}$. The present study is aimed at investigating the inhibitive properties of ethanol extract of vernonia amygdalina on the corrosion of mild steel in $\mathrm{H}_{2} \mathrm{SO}_{4}$. Vernonia amygdalina is an annual, erect, branched and hairy herb, having a height of $30-120 \mathrm{~cm}$. The leaves of the plant are simple and alternate. The plant is geographically distributed in West African countries including Nigeria [30]. According to Gill [31], the extract of vernonia amygdalina is medicinal and is used in curing headache and fever. Notable chemical constituents of ethanol extract of vernonia amygdalina are glycosidevernoniside, vernonium and 15 sesquiterpenes lactones [31].

\section{Experimental details \\ Materials preparation}

Mild steel of composition (wt\%) Mn (0.6), P (0.36), C (0.15), S (0.07) and Fe (98.79) was used for the study. The sheet was mechanically press-cut to form different coupons, each of dimension, $5 \times 4 \times 0.11 \mathrm{~cm}$. Each coupon was degreased by washing with ethanol. The washed sample was dipped in acetone, removed and allowed to dry in air before use. All reagents used for the study were analar grade and double distilled water was used for their preparation.

\section{Extraction of plants}

Samples of vernonia amygdalina obtained from the Akwa Ibom State garden were dried, ground and soaked in a solution of ethanol. After 48 hours, the sample was cooled and filtered. The filtrate was subjected to evaporation (in order to leave the sample free of the ethanol) using a rotary evaporator. The stock solution of the extract so obtained was used in preparing $0.1,0.2,0.3,0.4$ and 0.5 $\mathrm{g} / \mathrm{L}$ of $2.5 \mathrm{M} \mathrm{H}_{2} \mathrm{SO}_{4}$ and $0.1 \mathrm{M}$ for used in gasometric/thermometric and gravimetric analysis, respectively.

\section{Gasometric method}

Hydrogen evolution measurements were carried out at 303 and $333 \mathrm{~K}$ as described in literature [12]. From the volume of hydrogen gas evolved per minute, corrosion rate $(\mathrm{CR})$, inhibition efficiency $(\% \mathrm{I})$ and degree of surface coverage, were calculated using Equations 1, 2 and 3, respectively.

$$
\begin{aligned}
& \% I=\left(1-\frac{V_{H t}^{1}}{V_{H t}^{o}}\right) x 100 \\
& \mathrm{CR}=\left(\mathrm{V}^{0}{ }_{\mathrm{Ht}}-\mathrm{V}^{\prime}{ }_{\mathrm{Ht}}\right) / \mathrm{t}
\end{aligned}
$$




$$
\theta=\% \mathrm{I} / 100=\left(1-\frac{V_{H t}^{l}}{V_{H t}^{o}}\right)
$$

where $\mathrm{V}^{1}{ }_{\mathrm{Ht}}$ is the volume of hydrogen gas at time $\mathrm{t}$ for inhibited solution and $\mathrm{V}_{\mathrm{Ht}}^{\mathrm{O}}$ is the volume of hydrogen gas evolved at time $t$ for uninhibited solution.

\section{Thermometric method}

Measurements of temperature were carried out according to the method described by Eddy and Ebenso [13]. From the rise in temperature per minute, the reaction number $(\mathrm{RN})$ and inhibition efficiency were calculated using Equations 4 and 5.

$$
\begin{gathered}
R N\left({ }^{\circ} C \min ^{-1}\right)=\frac{T_{m}-T_{i}}{t} \\
\% I=\frac{R N_{a q}-R N_{w i}}{R N_{a q}} x 100
\end{gathered}
$$

where $R N_{a q}$ is the reaction number in the absence of inhibitors (blank solution), and $R N_{w i}$ is the reaction number of $2.5 \mathrm{M} \mathrm{H}_{2} \mathrm{SO}_{4}$ containing studied inhibitors.

\section{Gravimetric analysis}

In gravimetric experiment, a previously weighed metal (mild steel) coupon was completely immersed in $250 \mathrm{~mL}$ of the test solution in an open beaker. The beaker was inserted into a water bath maintained at a temperature of $30{ }^{\circ} \mathrm{C}$. After every 24 hours, each sample was withdrawn from the test solution, washed in a solution containing $50 \% \mathrm{NaOH}$ and $100 \mathrm{~g} / \mathrm{L}$ of zinc dust. The washed sample was dried with acetone before re-weighing. The difference in weight for a period of $168 \mathrm{~h}$ was taken as total weight loss. From the weight loss results, the inhibition efficiency $(\% \mathrm{I})$ of the inhibitor and degree of surface coverage were calculated using Equations 6 and 7, respectively,

$$
\begin{gathered}
\% \mathrm{I}=\left(1-\mathrm{W}_{1} / \mathrm{W}_{2}\right) \times 100 \\
\theta=1-\mathrm{W}_{1} / \mathrm{W}_{2}
\end{gathered}
$$

where $\mathrm{W}_{1}$ and $\mathrm{W}_{2}$ are the weight losses $\left(\mathrm{g} / \mathrm{dm}^{3}\right)$ for mild steel in the presence and absence of the inhibitor in $\mathrm{H}_{2} \mathrm{SO}_{4}$ solution, respectively, and $\theta$ is the degree of surface coverage of the inhibitor.

\section{Chemical analysis}

IR analysis was carried out using a Buck model 500M infra red spectrophotometer. The samples were prepared using nujol oil. Photochemical analysis of the extract was carried out according to the method reported by Onyeka and Nwabekwe [14]. 


\section{Results and discussions}

Fig. 1 shows the variation of weight loss with time during the corrosion of mild steel in $0.02-0.5 \mathrm{M} \mathrm{H}_{2} \mathrm{SO}_{4}$ at $303 \mathrm{~K}$. From the figure, it can be seen that weight loss of mild steel increases linearly with time, indicating that the rate of corrosion of mild steel in $\mathrm{H}_{2} \mathrm{SO}_{4}$ increases with time. Values of weight loss were also found to vary with concentration of $\mathrm{H}_{2} \mathrm{SO}_{4}$ in such a way that the trend of increase in weight loss with time was $0.5>0.1>0.02>0.01 \mathrm{M} \mathrm{H}_{2} \mathrm{SO}_{4}$. Fig. 2 shows the plot of variation of weight loss with time during the corrosion of mild steel in 0.1 $\mathrm{M} \mathrm{H}_{2} \mathrm{SO}_{4}$ in the presence of various concentrations of ethanol extract of vernonia amygdalina as an inhibitor. It was also observed that the addition of ethanol extract of Vernonia amagdalina to the corrodent led to a reduction in weight loss compared to that of the blank. This indicates that ethanol extract of vernonia amagdalina inhibited the corrosion of mild steel in $\mathrm{H}_{2} \mathrm{SO}_{4}$.

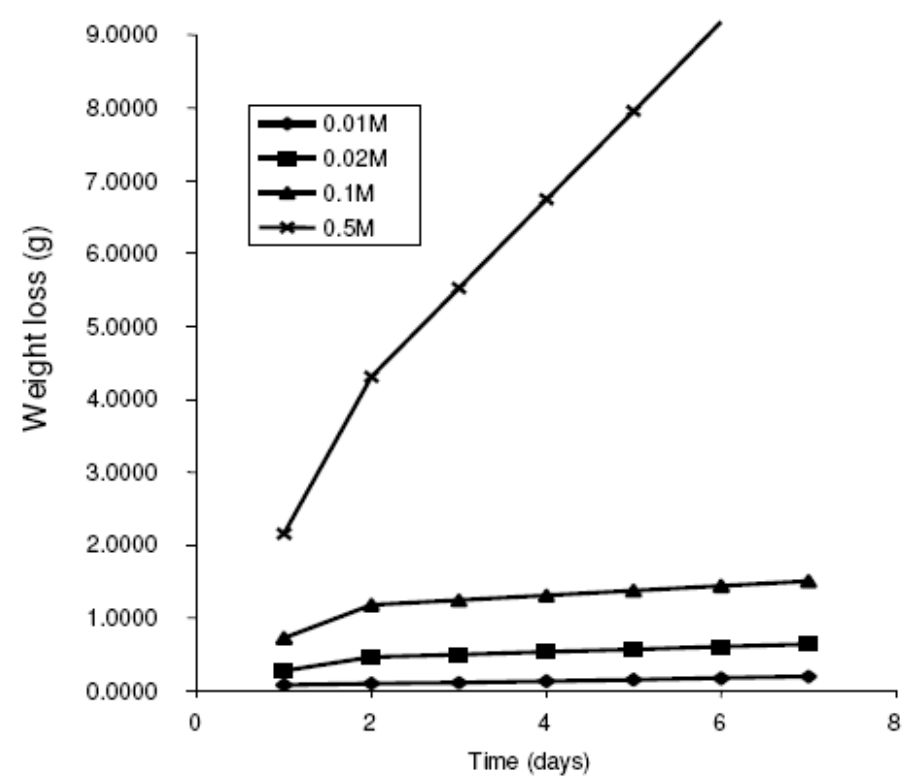

Figure 1. Variation of weight loss with time for the corrosion of mild steel in various concentrations of $\mathrm{H}_{2} \mathrm{SO}_{4}$ at $303 \mathrm{~K}$.

Fig. 3 shows the variation of volume of hydrogen gas evolved with time during the corrosion of mild steel in $1.0-2.5 \mathrm{M}$ of $\mathrm{H}_{2} \mathrm{SO}_{4}$. From the figure, it can be seen that the volume of hydrogen gas evolved increased with increase in the period of contact and with the concentration of $\mathrm{H}_{2} \mathrm{SO}_{4}$, indicating that the rate of corrosion of mild steel in $\mathrm{H}_{2} \mathrm{SO}_{4}$ increased as the period of contact and concentration of $\mathrm{H}_{2} \mathrm{SO}_{4}$ increase. Figs. 4 and 5 show the variation of volumes of hydrogen gas evolved with time for the corrosion of mild steel in $2.5 \mathrm{M} \mathrm{H}_{2} \mathrm{SO}_{4}$ containing various concentrations of ethanol extract of vernonia amygdalina at 303 and $333 \mathrm{~K}$, respectively. From the figures, it is seen that the volume of hydrogen gas evolved, hence the rate of corrosion of mild steel, also increased with increase in the concentration of ethanol extract of vernonia amagdalina and with the period of contact. It was also observed that the volume of hydrogen gas 
evolved by the blank (2.5 $\left.\mathrm{M} \mathrm{H}_{2} \mathrm{SO}_{4}\right)$ was greater than the volumes evolved by solutions containing various concentrations of ethanol extract of vernonia amygdalina, indicating that the extract inhibited the corrosion of mild steel in $\mathrm{H}_{2} \mathrm{SO}_{4}$.

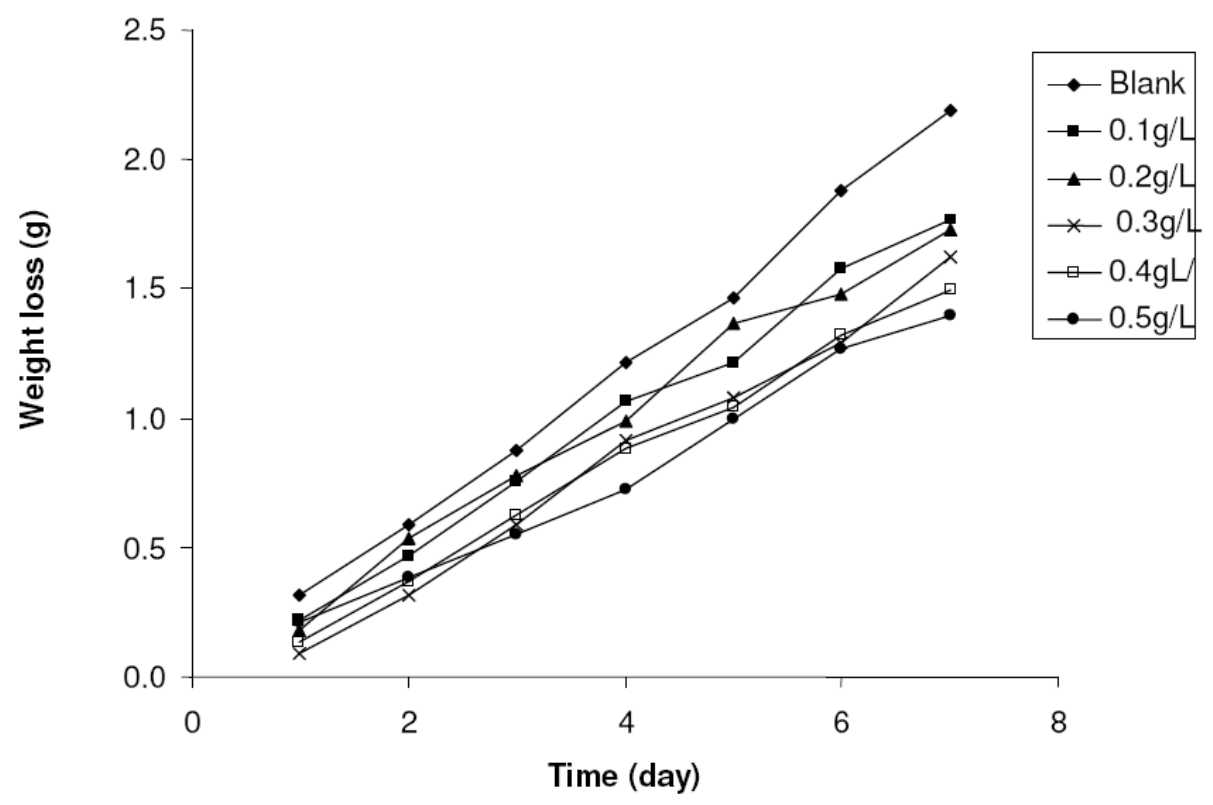

Figure 2. Variation of weight loss with time for the corrosion of mild steel in $\mathrm{H} 2 \mathrm{SO} 4$ containing various concentrations of ethanol extract of vernonia amygdalina.

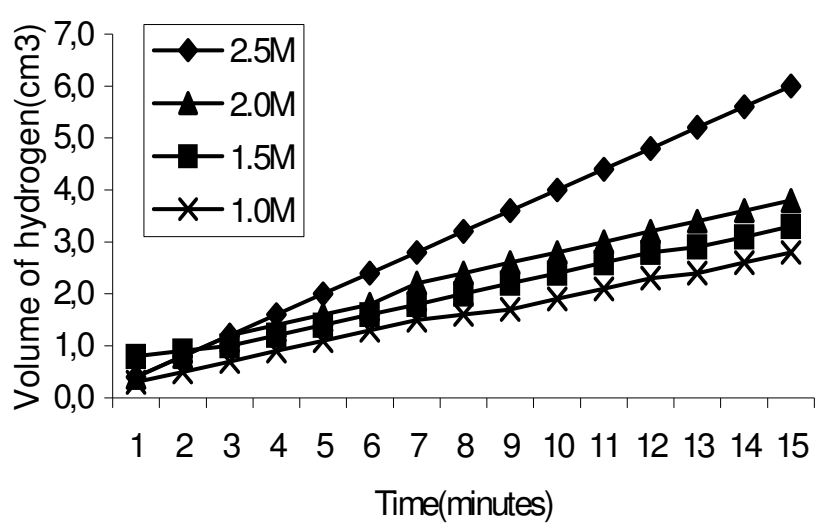

Figure 3. Variation of the volume of hydrogen gas evolved with time for the corrosion of mild steel in various concentrations of $\mathrm{H}_{2} \mathrm{SO}_{4}$.

The reaction number $(\mathrm{RN})$ obtained from thermometric measurement, for the corrosion of mild steel in $2.5 \mathrm{M} \mathrm{H}_{2} \mathrm{SO}_{4}$ was 0.095 . In the presence of various concentrations of ethanol extract of vernonia amygdalina, values of reaction number decreased to the range of 0.05 to $0.075^{\circ} \mathrm{C} / \mathrm{min}$. The decrease in $\mathrm{RN}$ in the presence of ethanol extract of vernonia amaygdalina also indicated that ethanol extract of vernonia amygdalina retarded the corrosion of mild steel in $\mathrm{H}_{2} \mathrm{SO}_{4}$. 


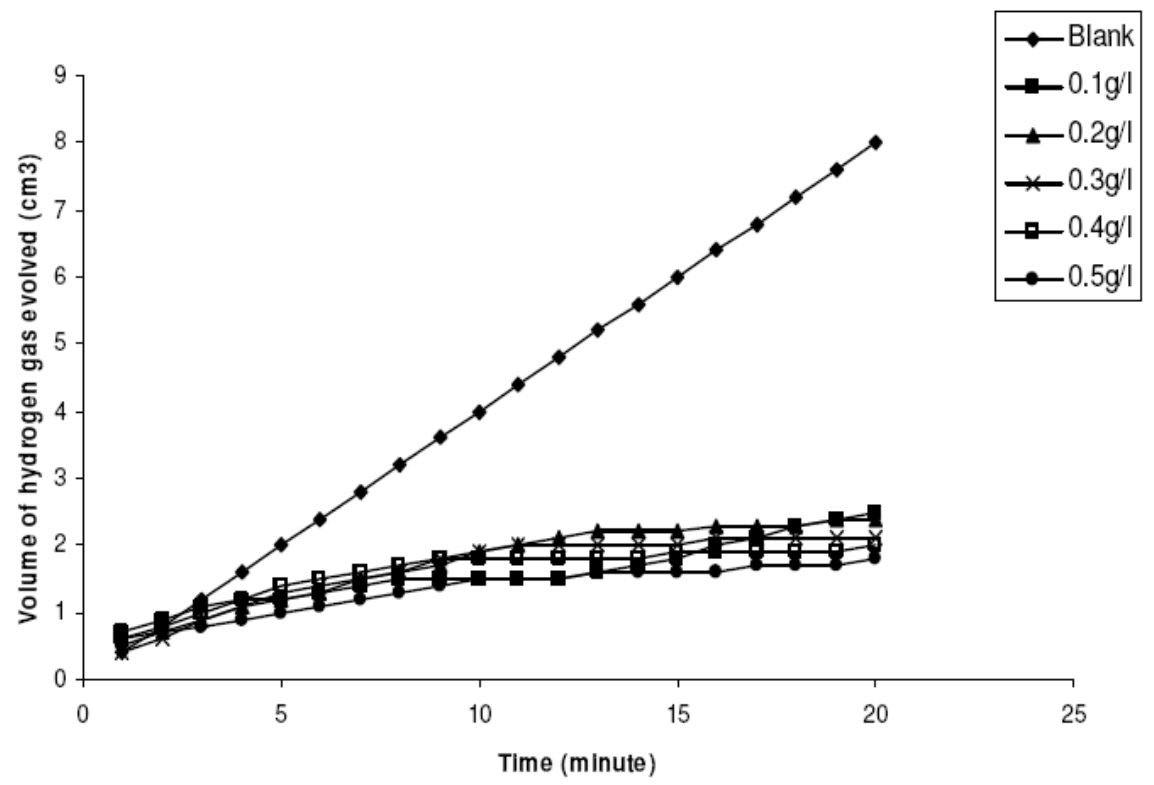

Figure 4. Variation of the volume of hydrogen gas evolved with time for the corrosion of mild steel in $\mathrm{H}_{2} \mathrm{SO}_{4}$ containing various concentrations of ethanol extract of vernonia amygdalina at $303 \mathrm{~K}$.

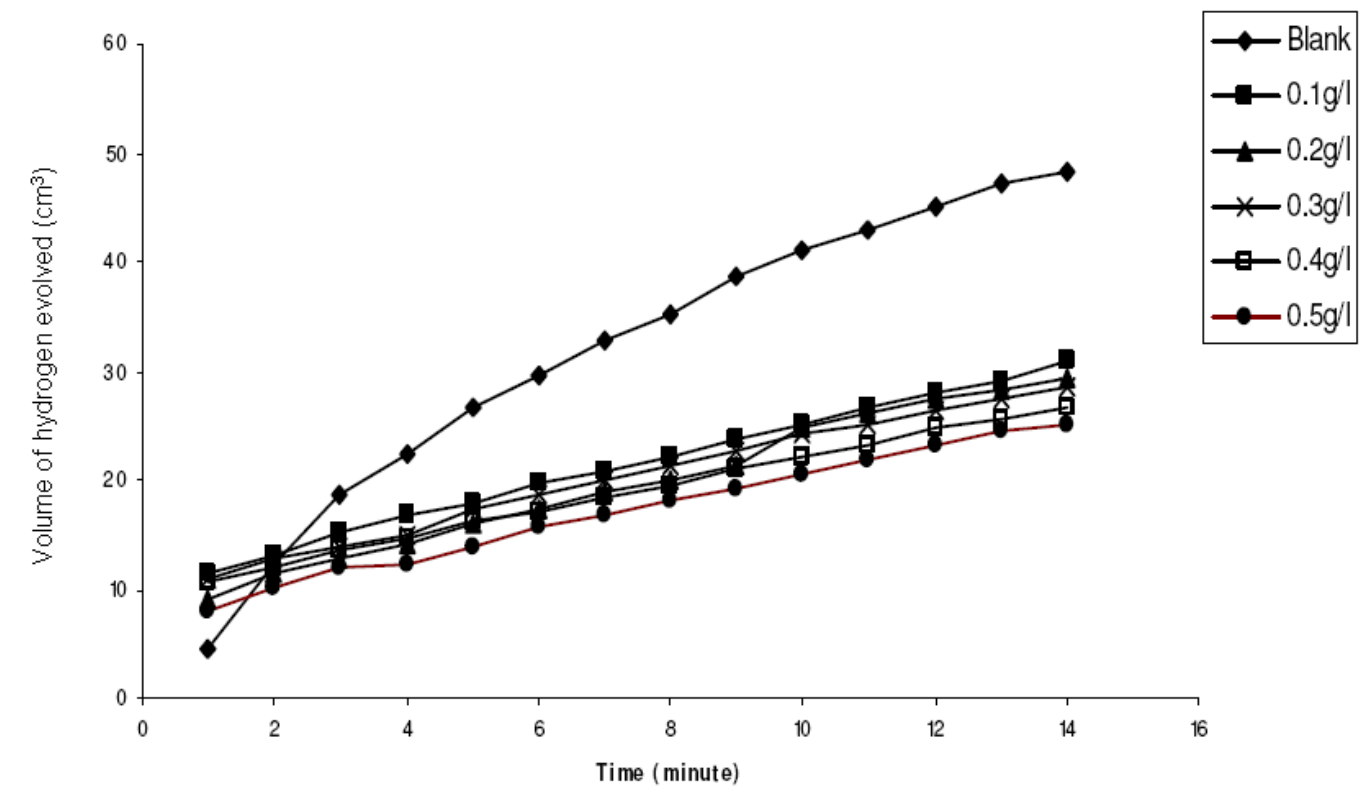

Figure 5. Variation of the volume of hydrogen gas evolved with time for the corrosion of mild steel in $\mathrm{H}_{2} \mathrm{SO}_{4}$ containing various concentrations of ethanol extract of vernonia amygdalina at $333 \mathrm{~K}$.

\section{Effect of ethanol extract of vernonia amygdalina on the corrosion of mild steel}

Ethanol extract of vernonia amygdalina decreased the rate of weight loss, the rate of evolution of hydrogen gas and the rate of change of temperature. This confirms that ethanol extract of vernonia amygdalina inhibits the corrosion of mild steel in $\mathrm{H}_{2} \mathrm{SO}_{4}$. Values of inhibition efficiency (\% I) and corrosion rates obtained from weight loss, gasometric and thermometric methods (for the inhibition of the corrosion of mild steel in $\mathrm{H}_{2} \mathrm{SO}_{4}$ by various concentrations of ethanol extract of vernonia amygdalina) are recorded in Table 1. The results 
indicate that inhibition efficiencies obtained from weight loss measurement are higher than those obtained from gasometric and thermometric methods, indicating that the average inhibition efficiency of the inhibitor is better than its instantaneous inhibition efficiencies. However, data obtained from gasometric and thermometric methods strongly correlated with those obtained from weight loss measurements $(r=0.9803$ and 0.9151 for gasometry and thermometry data, respectively), confirming that ethanol extract of vernonia amaygdalina is a good inhibitor for the corrosion of mild steel in $\mathrm{H}_{2} \mathrm{SO}_{4}$.

Table 1. Values of inhibition efficiency and degree of surface coverage for the inhibition of the corrosion of mild steel at various concentrations of ethanol extract of vernonia amygdalina.

\begin{tabular}{|c|c|c|c|c|c|c|c|c|}
\hline \multirow{2}{*}{$\begin{array}{l}\text { Con. } \\
\text { (g/L) }\end{array}$} & \multicolumn{4}{|c|}{ Gasometric } & \multicolumn{2}{|c|}{ Weight loss } & \multicolumn{2}{|c|}{ Thermometric } \\
\hline & $\begin{array}{c}\% \mathbf{I} \\
(303 \mathrm{~K})\end{array}$ & $\begin{array}{c}\mathbf{C R} \\
\left(\mathrm{cm}^{3} / \mathbf{m i n}\right) \\
(303 \mathrm{~K})\end{array}$ & $\begin{array}{c}\% \mathbf{I} \\
(333 \mathrm{~K})\end{array}$ & $\begin{array}{c}\text { CR } \\
\left(\mathrm{cm}^{3} / \mathbf{m i n}\right) \\
(333 \mathbf{~ K})\end{array}$ & $\begin{array}{c}\% \mathbf{I} \\
(303 \mathrm{~K})\end{array}$ & $\begin{array}{c}\text { CR } \\
\left(\mathrm{g} / \mathrm{cm}^{-3} \mathbf{h}^{-1}\right) \\
(303 \mathbf{K})\end{array}$ & $\begin{array}{c}\% \mathbf{I} \\
(303 \mathrm{~K})\end{array}$ & $\begin{array}{c}\text { CR } \\
\left({ }^{\circ} \mathrm{C} / \mathrm{min}\right) \\
(\mathbf{3 0 3} \mathrm{K})\end{array}$ \\
\hline 0.1 & 76.32 & 0.090 & 37.00 & 1.44 & 89.94 & 0.313 & 21.05 & 0.075 \\
\hline 0.2 & 76.32 & 0.090 & 40.53 & 1.39 & 90.35 & 0.261 & 21.05 & 0.075 \\
\hline 0.3 & 77.63 & 0.085 & 44.27 & 1.26 & 91.59 & 0.254 & 21.05 & 0.075 \\
\hline 0.4 & 81.58 & 0.070 & 44.93 & 1.23 & 93.59 & 0.250 & 47.37 & 0.050 \\
\hline 0.5 & 82.89 & 0.065 & 46.92 & 1.15 & 95.75 & 0.206 & 47.37 & 0.050 \\
\hline
\end{tabular}

\section{Effect of temperature}

The effect of temperature on the corrosion reaction of mild steel in the absence and presence of ethanol extract of vernonia amygdalina was investigated using Arrhenius equation,

$$
\log \frac{C R_{2}}{C R_{1}}=\frac{E_{a}}{2.303 R}\left(\frac{1}{T_{1}}-\frac{1}{T_{2}}\right)
$$

From hydrogen evolution measurements, values of $\mathrm{CR}\left(\mathrm{cm}^{3} / \mathrm{min}\right)$ were calculated and substituted into equation 6 to obtain $E_{a}$ values. These values (Table 2) ranged from 74.00 to $77.44 \mathrm{~kJ} / \mathrm{mol}$, indicating that vernonia amygdalina is adsorbed on the surface of mild steel by physical adsorption [3]. Also, the average value of $E_{a}$ obtained for the blank $(36.00 \mathrm{~kJ} / \mathrm{mol})$ was lower than values obtained for systems containing various concentrations of ethanol extract of vernonia amygdalina, indicating that this extract retards the corrosion of mild steel in $\mathrm{H}_{2} \mathrm{SO}_{4}$ [19-21]. 
Table 2. Some thermodynamic parameters for the adsorption of ethanol extract of vernonia amaydalina on the surface of mild steel.

\begin{tabular}{ccc}
\hline Concentration $(\mathbf{g} / \mathbf{L})$ & $\mathbf{E}_{\mathbf{a}}(\mathbf{J} / \mathbf{m o l})$ & $\mathbf{Q}_{\text {ads }}(\mathbf{k J} / \mathbf{m o l})$ \\
\hline Blank & 36.00 & - \\
0.1 & 74.24 & -38.25 \\
0.2 & 72.86 & -52.34 \\
0.3 & 77.44 & -47.62 \\
0.4 & 74.00 & -39.17 \\
0.5 & 72.78 & -49.82 \\
\hline
\end{tabular}

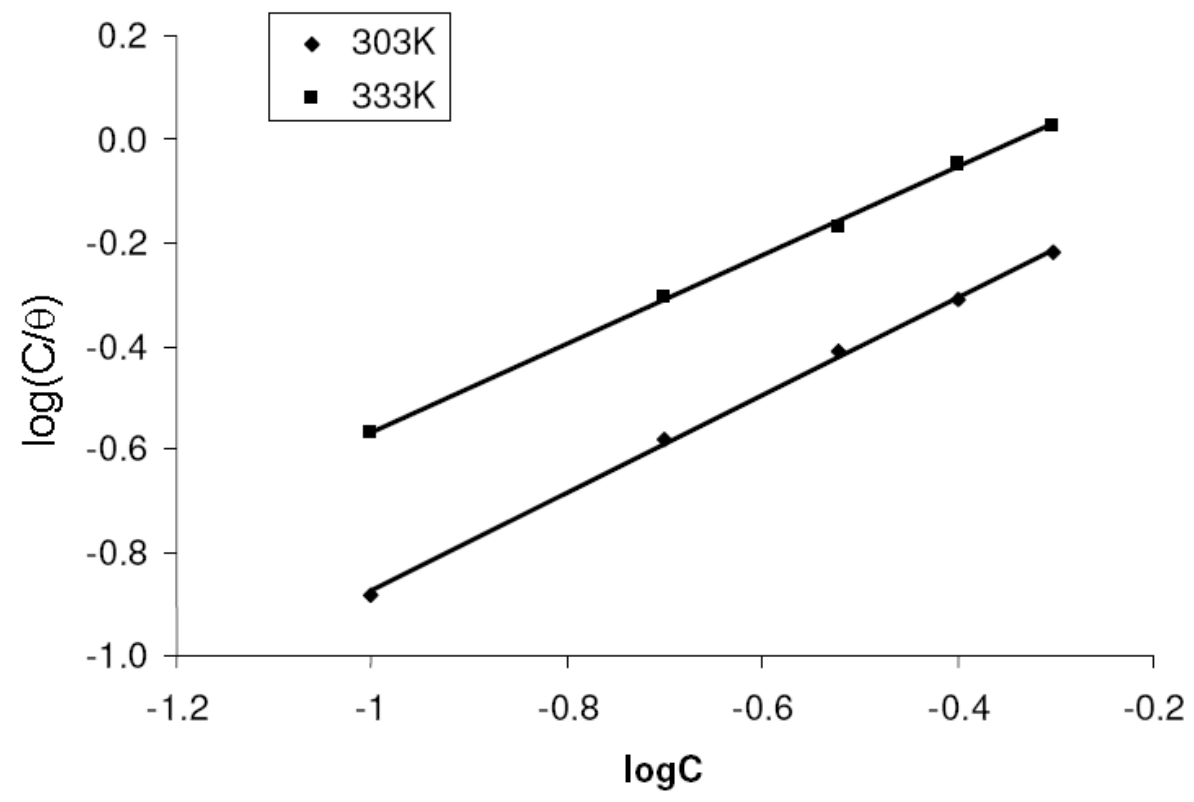

Figure 6. Langmuir isotherm for the adsorption of ethanol extract of vernonia amygdalina on the surface of mild steel.

\section{Thermodynamics/adsorption consideration}

The heat adsorbed during the inhibition of the corrosion of mild steel by ethanol extract of vernonia amygdalina was calculated using equation 9 [1-2]

$$
Q_{a d s}=2.303 R\left[\log \left(\frac{\theta_{2}}{1-\theta_{2}}\right)-\log \left(\frac{\theta_{1}}{1-\theta_{1}}\right)\right] x\left(\frac{T_{1 X} T_{2}}{T_{2}-T_{1}}\right) k J m o l^{-1}
$$

Values of $\mathrm{Q}_{\mathrm{ads}}$ are recorded in Table 2. These values ranged from -38.2481 to $52.3433 \mathrm{~kJ} / \mathrm{mol}$, indicating that the adsorption of ethanol extract of vernonia 
amygdalina on mild steel surface is exothermic [17-19]. Also, since the reactions were carried out under constant pressure, the heat adsorbed is also equal to the enthalpy change [22-23].

Table 3. Langmuir adsorption parameters for the adsorption of ethanol extract of vernonia amygdalina on the surface of mild steel.

\begin{tabular}{cccccc}
\hline \multirow{3}{*}{} & Temperature (K) & $\log \mathbf{K}$ & slope & $\Delta \mathbf{G}_{\text {ads }}(\mathbf{k J} / \mathbf{g})$ & $\mathbf{R}^{2}$ \\
\cline { 2 - 6 } & 303 & 0.0723 & 0.9475 & -11.56 & 0.9989 \\
& 333 & 0.2843 & 0.8518 & -11.74 & 0.9996 \\
\hline
\end{tabular}

Values of degree of surface coverage calculated from hydrogen evolution measurements have been used to evaluate the adsorption characteristics of ethanol extract of vernonia amygdalina on mild steel surface. The data obtained were found to fit Langmuir adsorption isotherm. The assumptions of Langmuir adsorption isotherm can be represented by equation below 10 [19-23]:

$$
\mathrm{C} / \theta=1 / \mathrm{k}+\mathrm{C}
$$

which can also be written as follows,

$$
\log (\mathrm{C} / \theta)=\log \mathrm{C}-\log \mathrm{K}
$$

By plotting values of $\log (\mathrm{C} / \theta)$ versus $\log \mathrm{C}$, linear plots were generated (Fig. 6), confirming that the experimental data fitted the Langmuir adsorption isotherm for the adsorption of ethanol extract of vernonia amygdalina on mild steel, meaning that there is no interaction between the adsorbed species..

Values of free energy of adsorption, $\Delta \mathrm{G}_{\mathrm{ads}}$, of ethanol extract of vernonia amygdalina on mild steel surface were calculated using equation 12 [23-27]

$$
\Delta \mathrm{G}_{\mathrm{ads}}=-2.303 \mathrm{RT} \log (55.5 \mathrm{~K})
$$

where $\mathrm{R}$ is the gas constant, $\mathrm{T}$ is the temperature and $\mathrm{K}$ is the equilibrium constant of adsorption of ethanol extract of vernonia amygdalina on the surface of mild steel, and 55.5 is the concentration of water in the solution. Values of $\Delta \mathrm{G}_{\mathrm{ads}}$ calculated from equation 12 are recorded in Table 3 . These values are negative, indicating spontaneous adsorption of the inhibitor on the surface of mild steel [28-29].

In order to further support the adsorption behaviour of the inhibitor on the surface of mild steel, IR spectroscopy was employed. Fig. 7 shows the IR spectrum of ethanol extract of vernonia amydalina alone. Fig. 8 shows the IR spectrum of the corrosion product (without the inhibitor), while Fig. 9 shows the IR spectrum of the corrosion product when ethanol extract of vernonia amygdalina was used as an inhibitor. From Fig. 7, it is seen that the extract exhibited broad adsorption band at $3402.06 \mathrm{~cm}^{-1}$ (peak height $\left.=56.880 \mathrm{~cm}\right)$, indicating the presence of alcohol or phenol functional group (i.e $-\mathrm{OH}$ ). An 
adsorption band was also found at $1046.01 \mathrm{~cm}^{-1}$ (peak height $=87.459 \mathrm{~cm}$ ), suggesting the presence of $-\mathrm{CO}$ stretch.

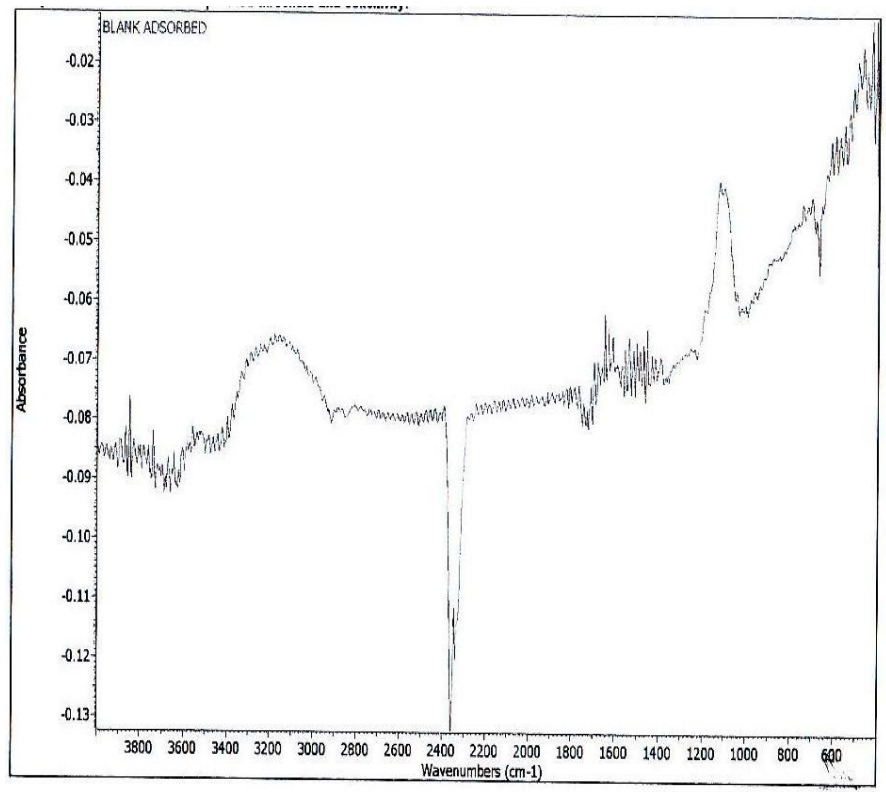

Figure 7. IR spectrum of the corrosion product (without the inhibitor).

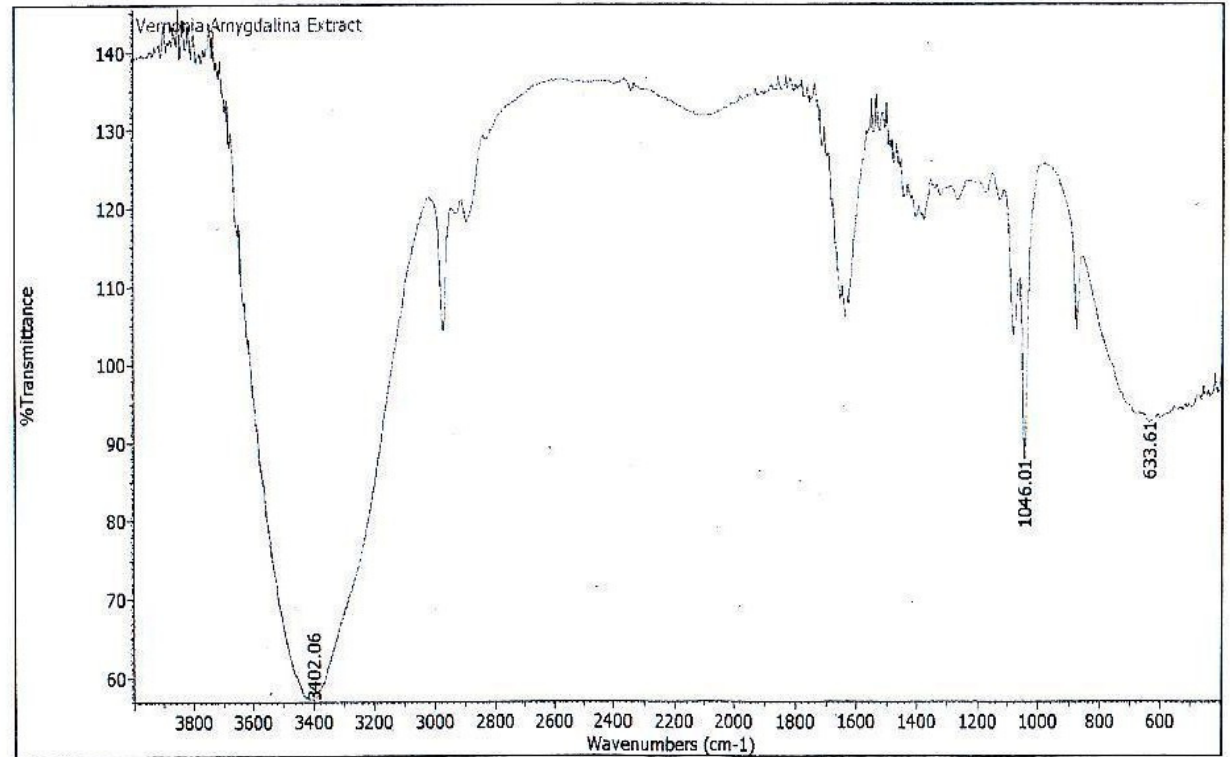

Figure 8. IR spectrum of ethanol extract of vernonia amygdalina.

The adsorption band at $633.61 \mathrm{~cm}^{-1}$ (peak height $=92.300 \mathrm{~cm}$ ) suggests the presence of carbon-carbon triple bond (i.e., alkyne type of compound). However, in the presence of the inhibitor, IR spectrum of the corrosion product revealed that the $-\mathrm{OH}$ stretch $\left(3407.06 \mathrm{~cm}^{-1}\right)$ was shifted to $3435.22 \mathrm{~cm}^{-1}$ and the $\mathrm{C}=\mathrm{O}$ stretch $\left(1046.01 \mathrm{~cm}^{-1}\right)$ was shifted to $1632.74 \mathrm{~cm}^{-1}$, while $\mathrm{C}-\mathrm{H}$ bend $\left(633.61 \mathrm{~cm}^{-}\right.$ 
$\left.{ }^{1}\right)$ was missing, indicating that there is interaction between the ethanol extract of vernonia amygdalina and the surface of mild steel.

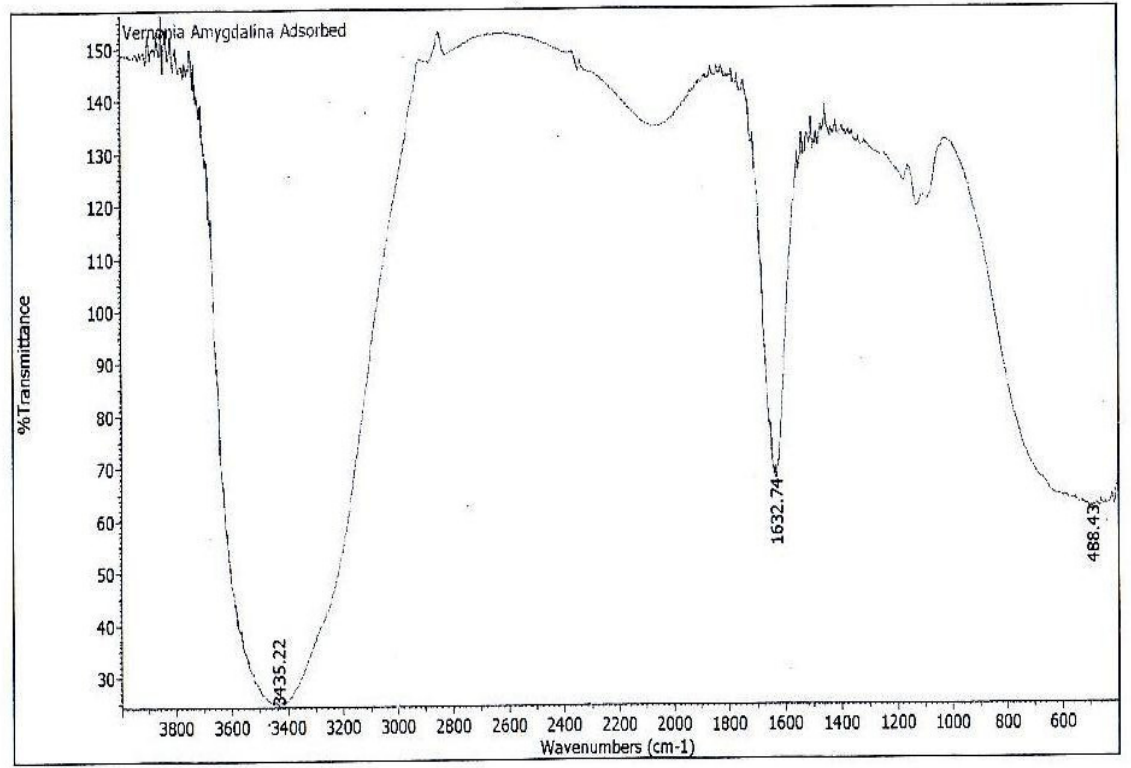

Figure 9. IR spectrum of the corrosion product showing adsorption in the presence of ethanol extract of vernonia amygdalina.

Phytochemical composition of aqueous and ethanol extract of vernonia amygdalina

The phytochemical composition of ethanol extract of vernonia amygdalina is shown in Table 4. The results indicated that the aqueous extract does not contain saponnins, terpenes, tannins, flavanoids, phlobatannins, anthraquinones, cardiac glycoside and alkaloid, while the ethanol extract contains all of them, except flavanoid and phlobatannins. This indicates that the inhibition efficiency of the extract is due to the presence of some or all of the above listed phytochemical constituents. Eddy and Ebenso [1] also stated that sapponins, tannins and alkaloids are active constituents of most green inhibitors.

Table 4. Phytochemical constituents of aqueous and ethanol extract of vernonia amygdalina.

\begin{tabular}{lcc}
\hline Phytochemicals & Aqueous extract & Ethanol extract \\
\hline Saponins & - & ++ \\
Terpenes & - & ++ \\
Tannins & - & ++ \\
Flavonoid & - & - \\
Phlobatannins & - & - \\
Anthraquinones & - & +++ \\
Cardiac glycoside & - & ++ \\
Alkaloids & - & ++ \\
\hline++ highly present, $++=$ moderately present, - - absent or present in negligible quantity.
\end{tabular}




\section{Conclusion}

From the study, the following conclusions are made:

1. ethanol extract of vernonia amygdalina is a good inhibitor for the corrosion of mild steel in $\mathrm{H}_{2} \mathrm{SO}_{4}$;

2. the inhibitor acts by being adsorbed on the surface of mild steel according to classical Langmuir adsorption isotherm;

3. adsorption of ethanol extract of vernonia amygdalina on the surface of mild steel is spontaneous and occurs by physical adsorption.

\section{Acknowledgement}

The authors are grateful to Ndifreke Nde, Isangedihi Ating and S.A. Umoren for supporting the research. The authors are also grateful to Mrs. Edikan Nnabuk Eddy for typesetting the work.

\section{References}

1. N.O. Eddy and E.E. Ebenso, Afri. J. Pure Appl. Chem. 2 (2008) 046.

2. $\quad$ N.O. Eddy and S.A. Odoemelam, Mat. Sci. (India) 4 (2008) 9.

3. A. Al-Sehaibani, Mater. Wissen. Werkst. Tech. 31 (2000) 1060.

4. G.O. Avwiri and F.O. Igho, Materials Letter 57 (2001) 3705.

5. E. H. El Ashry, A. El Nemir, S. A. Esawy and S. Ragab, Electrochimica Acta 51 (2006) 3957.

6. A.Y. El-Etre and M. Abdallah, Corros. Sci. 42 (2000) 731.

7. P.C. Okafor, M.I. Ikpi, I.E. Uwah, E.E. Ebenso, U.J. Ekpe and S.A. Umoren, Corros. Sci. 50 (2008) 2310.

8. $\quad$ M.I. Awad, J. Appl. Electrochem. 36 (2006) 1163.

9. S.A. Odoemelam and N.O. Eddy, J. Surf. Sci. Technol. 24 (2008) 1.

10. S. Rajendran, S.V. Ganga, J. Arockiaselvi, and A.J. Amalraj, Bull. Electrochem. 21 (2005) 367.

11. M.G. Sethuran and P.B. Raja, Pigment \& Resin Technol. 34 (2006) 327.

12. E.E. Ebenso, Bull. Electrochem. 19 (2003) 209.

13. S.A. Odoemelam and N.O. Eddy, J. Surf. Sci. \& Technol. 24 (2008) 1.

14. E.U. Onyeka and I.O. Nwabekwe, Nigerian Food J. 25 (2007) 67.

15. O.K. Abiola, N.C. Oforka and E.E. Ebenso, JCSE. 5 (2004) 1.

16. N.O. Eddy and A.S. Ekop, Mat. Sci. 4 (2008) 10.

17. P. Atkins, Physical Chemistry, $7^{\text {th }}$ edition, Oxford: Oxford press (2002).

18. K.K. Sharma and L.K. Sharma, A textbook of physical chemistry, $4^{\text {th }}$ revised ed., India: Vikas Pub. House. PVT Ltd. (2004).

19. M. Abdallah, Corrosion Sci. 46 (2004) 1981.

20. S. Acharya and S.N. Upadhyay, Trans. Indian Inst. Met. 57 (2004) 297.

21. Y.K. Agrawal, J.D. Talati, M.D. Shah, M.N. Desai and N.K. Shah, Corrosion Sci. 46 (2003) 633. 
22. H. Ashassi-Sorkhabi, B. Shaabani and D. Seifzadeh, Appl. Surf. Sci. 239 (2005) 154.

23. A. Yurt, G. Bereket, A. Rivrak, A. Balaban and B. Erk, J. Appl. Electrochem. 35 (2005) 1025.

24. S.A. Umoren, E.E. Ebenso, P.C. Okafor and O. Ogbode, Pigment \& Resin Technol. 35 (2006a) 346.

25. S.A. Umoren, I.B. Obot, E.E. Ebenso, P.C. Okafor, O. Ogbobe and E.E. Oguzie, Anti-Corrosin Methods and Materials 53 (2006b) 277.

26. S.A. Umoren, O. Ogbobe, E.E. Ebenso and U.J. Ekpe, Pigment \& Resin Technol. 35 (2006c) 284.

27. E.E. Oguzie, Pigment and Resin Technol. 34 (2005) 321.

28. E.E. Ebenso, U.J. Ekpe, E. Jackson, O.K. Abiola and N.C. Oforka, J. Appl. Polym. Sci. 100 (2004) 2889.

29. N.O. Eddy, A.O. Odiongenyi and S.A. Odoemelam, Adv. in Nat. \& Appl. Sci. 2 (2008) 35.

30. A. Mann, M. Gbate and A.N. Umar, Medicinal and Economic Plants of Nupeland. Jube-Evans Books Publication. Bida, Nigeria.

31. L.S. Gill, Ethnomedical uses of plants in Nigeria. UNIBEN press, Benin city, Nigeria. 